\title{
Introducción propedéutica a la tutela procesal del medio ambiente en el Perú
}

\section{Carlos Alberto Matheus López}

\author{
"La iluminación ocurre en el instante entre dos respiraciones"
}

Proverbio budista

\section{Nociones previas}

\section{El concepto de medio ambiente}

Debemos inicialmente señalar que el concepto de medio ambiente posee una naturaleza evolutiva y dinámica, la cual se encuentra en constante desarrollo. ${ }^{\prime}$ Observándose que, así como el medio ambiente mismo ha sufrido una progresiva evolución, de igual modo, la ha experimentado su concepto jurídico. Siendo ello obvio, dado que solo cabría hablar de un "medio ambiente natural e incólume" refiriéndonos a la época humana más primitiva - previa al uso de herramientas- en la cual el hombre aún no había operado sobre la naturaleza produciendo alteraciones artificiales de su entorno. ${ }^{2}$

Resulta claro que se ha confundido el presupuesto metajurídico con el concepto jurídico del medio ambiente, olvidándose que el derecho - si bien analiza la realidad y no puede concebirse sin ella - como todas las

1 En este sentido Silvia Jaquenod de Zsögön, Iniciación al derecho ambiental, Dykinson, 1999, Madrid, p. 60. Nos señala —refiriéndose al Derecho Ambiental-que este es «también dinámico porque, al regular conductas susceptibles de afectar sistemas naturales, no puede sino responder a la propia dinámica de la naturaleza. Y puesto que esta se comporta de forma sumamente variable, el derecho ambiental, sus principios y la legislación ambiental, deben ir consolidando de modo casi permanente la adaptación a la realidad que pretenden regular, manteniendo la eficacia legal».

2 Con tal parecer Jesús Jordano Fraga, La protección del derecho a un medio ambiente adecuado, José María Bosch (editor), Barcelona, 1995, p. 77. 
ciencias que estudian un objeto ha de formular desde sus propias perspectivas sus elaboraciones. Habiendo sido la causa de esta confusión el hecho de que el medio ambiente viene primero elaborado por las ciencias no jurídicas, siendo posteriormente reelaborado por el derecho, con un consecuente error de perspectiva, puesto que aquel concepto que sirve como punto de partida - de las ciencias no jurídicas - no necesariamente servirá como punto de llegada. ${ }^{3}$

Por otra parte, si bien resulta compleja la proposición de una definición acabada sobre el medio ambiente, dado el carácter dinámico del concepto, podemos considerar a este como el conjunto equilibrado de componentes naturales que conforman una determinada zona, en un determinado momento, que representa el sustrato físico de la actividad de todo ser vivo y es susceptible a la modificación por la actividad del ser humano. ${ }^{4}$

Adicionalmente, debemos reconocer que el concepto jurídico de medio ambiente resulta una noción polivalente, pues en una primera acepción importa un bien jurídico y en la segunda una materia objeto de competencia.

El medio ambiente es un bien jurídico constitucionalizado 5 (importa un valor objeto de protección privilegiada por el ordenamiento jurídico), ${ }^{6}$ colectivo (pues su disfrute y principalmente su titularidad atańe a la sociedad en su conjunto); y posee un carácter complejo (dado que pese a ser un bien jurídico único - como vimos- se halla formado por diferentes elementos en su composición).

Como materia de competencia, importa — dada la progresiva intervención legislativa sobre él- la definición de los diversos campos de ac-

3 Jordano, op. cit., p. 75.

4 Eulalia Moreno Trujillo, La protección jurídico-privada del medio ambiente y la responsabilidad por su deterioro, José María Bosch (editor), Barcelona, 1991, p. 47.

5 Nuestra actual Constitución de 1993 reconoce en su artículo $2^{\circ}$ inciso $22^{\circ}$ que "Toda persona tiene derecho: [...] A la paz, a la tranquilidad, al disfrute del tiempo libre y al descanso, así como a gozar de un ambiente equilibrado y adecuado al desarrollo de su vida".

De igual forma, nos señala en su artículo $67^{\circ}$ que «El Estado determina la política nacional del ambiente. Promueve el uso sostenible de sus recursos naturales».

6 En tal forma, el "Código del medio ambiente y de los recursos naturales" (Decreto Legislativo $\mathrm{N}^{\circ}$ 613) nos señala que "Toda persona tiene el derecho irrenunciable a gozar de un ambiente saludable, ecológicamente equilibrado y adecuado para el desarrollo de la vida, y asimismo, a la preservación del paisaje y la naturaleza. Todos tienen el deber de conservar dicho ambiente [...]». 
tuación de las distintas administraciones públicas ${ }^{7}$ (en aspectos de gestión y producción normativa) como consecuencia del reconocimiento de la capacidad legislativa a instituciones territoriales distintas del estado. ${ }^{8}$

\section{El interés legítimo}

Hemos de ser conscientes que el ordenamiento jurídico se encuentra referido a la actividad humana (constituyendo así el conjunto de formas que confieren una estructura al quehacer social) ${ }^{9}$ e importa un universo de normas que inciden sobre las relaciones sociales y cuya función es organizar dichas relaciones, garantizando la realización práctica y la satisfacción de un conjunto de intereses. ${ }^{10}$ Por esta razón debe otorgar a los sujetos los instrumentos necesarios para la realización de sus intereses, los cuales son designados como "situaciones jurídicas subjetivas». ${ }^{11}$

De tal forma, la situación jurídica subjetiva importa la posición del sujeto frente a las reglas del derecho, la cual responde a una determinada valoración del ordenamiento jurídico respecto de la primacía o subordinación del interés que le sirve de presupuesto. Pudiendo observarse que cuando la situación jurídica subjetiva refleja la supremacía de un interés frente a otro, se dice que la misma es de ventaja, mientras que cuando aquella importa la subordinación de un interés frente a otro se dice que es de desventaja. A su vez, la situación jurídica de ventaja puede ser: activa cuando permite obrar para realizar el interés que le sirve de presupuesto, o inactiva, si ella no permite obrar para obtener dicho resultado (encontrándose en este segundo supuesto el interés legítimo). ${ }^{12}$

De tal modo, el interés legítimo se sitúa como una de las diversas formas de concretarse las situaciones jurídicas subjetivas surgidas de la

7 Pudiendo observarse la existencia de distintas competencias que en materia de medio ambiente poseen, respectivamente, tanto el gobierno central como los gobiernos locales y regionales.

8 Jordano, op. cit., pp. 78-84.

9 Con este parecer Vittorio Frosini, La estructura del derecho, Publicaciones del Real Colegio de España, Bolonia, 1974, p. 35.

10 Con este parecer Vittorio Breccia, Lina Bligliazzi Geri, Ugo Natoli, Francesco Busnelli, Derecho Civil, Vol. I, Universidad Externado de Colombia, Bogotá, 1992, pp. 1-3.

11 Con este parecer Breccia, Derecho Civil [...], op. cit., pp. 352-353.

12 Breccia, Derecho Civil [...], op. cit., pp. 353-356. 
relación entre la norma jurídica y el individuo, entendiéndose «legítimo» simplemente como protegido por el ordenamiento jurídico o como conforme a derecho. Donde los intereses legítimos no serían más que aquellos que son aceptados por el ordenamiento jurídico como dignos de tutela, aun de forma indirecta o refleja. ${ }^{13}$

Donde para el caso específico del medio ambiente, esta situación jurídica corresponde - por ejemplo- a aquellos particulares susceptibles de ser afectados por la contaminación industrial, los cuales poseen un interés legítimo en que las empresas industriales respeten sus compromisos legales porque, en el caso que se produjera una infracción, podrían verse perjudicados en su esfera de derechos e intereses. En tal caso, estos particulares adquieren el derecho de defenderse y oponerse a la actuación de la empresa correspondiente, donde esta posición tiene como principal cauce la acción judicial destinada a impulsar el reestablecimiento de la situación inicial o la reparación del daño que la transgresión haya podido causar. ${ }^{14}$

\section{El interés difuso medioambiental}

\section{La noción de grupo}

El concepto de grupo, si bien es utilizado por el ordenamiento jurídico, no aparece definido legalmente, siendo por esta razón encuadrado entre los entes que no poseen personalidad jurídica. ${ }^{15}$ Dado ello, podemos definir al grupo como aquel que consta de un determinado número de miembros, quienes para alcanzar un objetivo común (objetivo de grupo) se inscriben durante un período prolongado de tiempo, en un proce-

13 Lorenzo-Mateo Bujosa Vadell, La protección jurisdiccional de los intereses de grupo, José María Bosch editor, Barcelona, 1995, pp. 29-37; con similar parecer Breccia, Derecho Civil [...], p. 430. Nos señala que este importa una «situación de ventaja encaminada a la consecución de un resultado favorable, consistente, según los casos, en la conservación o en la modificación de una determinada realidad».

14 Bernard-Frank Masera, El deber industrial de respetar el ambiente. análisis de una situación pasiva de derecho público, Marcial Pons, Madrid, 1998, pp. 57-58.

15 Cosa la cual le genera - como veremos más adelante- un problema de acceso al proceso jurisdiccional, pues, al carecer de personalidad jurídica, consecuentemente, tampoco posee capacidad para ser parte ni capacidad procesal. 
so relativamente continuo de comunicación e interacción y desarrollan un sentimiento de solidaridad. Razón por la cual, cabe concluir, que el grupo es un sistema de interacción, no de organización, y que es la evolución social y la propia existencia de la sociedad de masas, lo que origina y explica la necesidad de que los grupos accedan al proceso. ${ }^{16}$

De otro lado, si bien no es necesaria una conciencia de grupo - por parte de todos los miembros integrantes - para que exista un interés de grupo, puede haber desconocimiento por parte de alguno de estos de la existencia de una dimensión colectiva del interés mismo, es evidente que esta conciencia colectiva facilita la organización de estos intereses y por tanto su protección jurisdiccional. ${ }^{17}$

En tal forma, resulta evidente que el interés grupal (denominado también colectivo o difuso) posee una extraordinaria importancia, pues su presencia predetermina la propia existencia del grupo. Siendo por esto necesario coordinar la consecuente tutela procesal del grupo con la existencia previa de un interés de este tipo. ${ }^{18}$

\section{El interés difuso}

Sobre la muy variada denominación de interés de grupo, difuso, colectivo, social o supraindividual, se hace referencia a aquel interés legítimo caracterizado por el goce de una relevancia especial en el plano del ordenamiento constitucional y de un reconocimiento confiado - principalmente- a normas de orden público. Intereses destinados a ser puestos de relieve y a proliferar en la realidad y, por ello, no reducibles a una serie preestablecida de figuras tampoco susceptibles de ser encuadradas en el ámbito de las categorías de situaciones jurídicas de ventaja ya conocidas. ${ }^{19}$

Como puede observarse, la indeterminación respecto a este clase de intereses hace buen maridaje con su propia denominación, entendiéndose

16 Joaquín Silguero Stagnan, La tutela jurisdiccional de los intereses colectivos a través de la legitimación de los grupos, Dykinson, Madrid, 1995, pp. 35-37.

17 Bujosa, La protección [...], op. cit., pp. 82-83.

18 Bujosa, op. cit., pp. 176-177.

19 Breccia, Derecho Civil [...], op. cit., p. 343. Si bien los autores consideran parcialmente incorrecto identificar el interés colectivo con el interés difuso sin más.

20 Macera, El deber [...], op. cit., p. 59. 
por algunos así, que interés difuso no es otra cosa que el interés que tiene todo miembro de la colectividad en que se respeten las normas que se han adoptado con atención a distintas finalidades..$^{20}$ Mientras que para otros, importa el interés de un sujeto jurídico en cuanto compartido - expandido - o compartible - expandible - por una universalidad, grupo, categoría, clase o género de los mismos; cuyo disfrute, ostentación y ejercicio son esencialmente homogéneos y fungibles, y que adolece de estabilidad y coherencia en su vinculación subjetiva, así como de concreción normativa orgánica en su tutela material y procesal. ${ }^{21}$

Es por todo ello, que debemos plantear una definición aproximada de interés difuso entendiendo así que aquel se refiere a la relación por la que un grupo más o menos determinado de personas pretende la evitar un perjuicio o la consecución de un beneficio en relación con un objeto no susceptible de apropiación exclusiva o en relación con diversos objetos susceptibles de apropiación exclusiva pero cualitativamente idénticos. Pudiendo observarse en estos intereses dos características básicas: por un lado, su carácter conflictual, puesto que importan situaciones jurídicomateriales de ventaja que resultan antagónicas frente a otros intereses ya reconocidos (frecuentemente los intereses de los ecologistas están en contraposición directa con los intereses de los urbanizadores o de las grandes empresas, e indirectamente, también contra los intereses de los trabajadores de aquellas); y por otro lado, su cierta indeterminación subjetiva, que suele — sin embargo - estar acompañada del dato de solidaridad e interdependencia de los miembros del grupo. ${ }^{22}$

\section{Caracteres propios en materia ambiental}

El interés difuso encuentra particular importancia en materia de medio ambiente, puesto que el Derecho ambiental es sustancialmente de carácter colectivo, aunque al logro de sus objetivos puedan concurrir normas de otra naturaleza, como son aquellas que regulan distintas relaciones o situaciones de vecindad. ${ }^{23}$

21 Lozano-Higuero y Manuel Pinto, «La protección procesal de los intereses difusos», Rufino García Blanco (editor), Madrid, 1983, p. 155.

22 Bujosa, La protección [...], op. cit., pp. 81-82.

23 Jaquenod, Iniciación [...], op cit., p. 59. Si bien señala además el autor que «la 
En tal forma, y partiendo de la noción de medio ambiente como bien jurídico, cabe señalar que los bienes jurídicos se distinguen en individuales y colectivos — sobre la base de su disfrute y titularidad—, siendo acorde a esta clasificación - el medio ambiente un bien jurídico colectivo, pues, aunque fuera posible imaginar una relación individual de cada ciudadano con el medio ambiente y lesiones del bien jurídico limitadas o circunscritas a una persona individual, es la sociedad en su conjunto la que ostenta la titularidad, cosa que se observa claramente en los supuestos de lesión del mismo, en los cuales la repercusión negativa del deterioro del medio ambiente afecta a la sociedad en su conjunto. ${ }^{24}$

Finalmente, debemos observar que los intereses difusos o de grupo se distinguen en dos categorías: si el interés grupal es el interés para obrar, ${ }^{25}$ los intereses objeto del proceso, en caso de existir, serán de tipo individual por lo que los denominaremos intereses individuales genéricos dado que - pese a su carácter propio e individual — son ejercitados a nivel de grupo (como es el caso de las reclamaciones de mínima cuantía, en las que el interés grupal está en el ejercicio de la acción colectiva mas el objeto reclamado es uno y quizá distinto para cada uno de sus miembros). De otro lado, cuando el interés del grupo sea de carácter sustantivo, se trata de un interés colectivo, como por ejemplo y específicamente para nuestro caso, en la defensa del medio ambiente. ${ }^{26}$

configuración del ambiente como bien jurídico colectivo no excluye la titularidad individual del derecho a un medio ambiente adecuado. Lejos de significar la exclusión de los individuos como titulares, la conceptualización del medio ambiente como bien jurídico colectivo implica el apoderamiento adicional de sujetos colectivos (asociaciones, entes públicos y grupos)».

24 Jordano, op. cit., pp. 80-81. Nos insta adicionalmente el autor a pensar en que "tan solo en la contaminación atmosférica o en la desaparición de una especie protegida. Aunque pueda existir una relación de cercanía o proximidad, en última instancia es la colectividad la que sufre el daño provocado. Ahora, si bien en determinados supuestos la persona individualmente considerada puede situarse en un primer plano, como sería el caso de un agricultor que ve contaminada el agua que usa para regar o el vecino de una fabrica que despide tóxicos, ello es solo consecuencia de la presencia de otra situación jurídica de ventaja, como en este caso es el derecho subjetivo de propiedad, el cual si bien es referible a la persona individual, la lesión al medio ambiente es reconducible a la colectividad».

25 Para una comprensión adecuada del interés para obrar ver Carlos Alberto Matheus López, Parte, tercero, acumulación e intervención procesal, Palestra, Lima, 2001, pp. 42 43.

26 Silguero, La tutela [...], op cit., p. 177. 


\section{Tratamiento procesal}

A continuación observaremos aquellos elementos del sistema procesal que deben ser analizados para el adecuado tratamiento de este tipo de intereses.

1) Respecto a la tutela jurisdiccional:

Debemos reconocer que - en puridad - no puede decirse que el grupo en cuanto tal sea titular de un derecho a la tutela judicial que salvaguarde su protección procesal, más ello no deviene en necesario, pues, siendo el grupo un supuesto de indeterminación transitoria del sujeto, el derecho a la tutela judicial debe predicarse respecto de cada una de las personas integrantes del grupo, dado que el individuo es el destinatario último de la tutela procesal. ${ }^{27}$

2) Sobre las capacidades procesales:

Si observamos el aspecto procesal de la cuestión, debemos detenernos en la doble vertiente del concepto de capacidad utilizado en relación con los sujetos que actúan como partes en el proceso. Primero, la capacidad para ser parte, entendida como la aptitud para ser demandante o demandado en un proceso, concepto que se construye paralelamente al de personalidad jurídica. Segundo, la capacidad procesal, definida como la aptitud para realizar actos válidos y eficaces en el proceso, concepto elaborado desde la capacidad de obrar. ${ }^{28}$

De otro lado, si entendemos a la capacidad para ser parte como aquella que se reconoce a todo el que posee capacidad jurídica (o lo que es lo mismo capacidad de goce), pudiendo por ello ser sujeto de una relación jurídico procesal, y con ello titular de los derechos, cargas y obligaciones que se derivan del proceso, observamos que corresponde tal aptitud a las personas naturales y jurídicas, al concebido para todo aquello que lo favorezca y a los patrimonios autónomos. ${ }^{29}$ Entonces, dado que la capacidad presupone personalidad, y puesto que no existe aquella en el grupo, tampoco puede afirmarse que aquel tenga por si mismo capacidad para ser parte, dado que se encuentran excluidas del concepto jurídico de grupo aquellas organizaciones dotadas de personalidad. ${ }^{30}$

27 Silguero, op. cit., p. 123.

28 Bujosa, La protección [...], op. cit., pp. 150-151.

29 Matheus, Parte, tercero [...], op. cit., pp. 34-35.

30 Silguero, La tutela [...], op. cit., p. 134. 
Por otra parte, si definimos a la capacidad procesal como la aptitud de realizar activa o pasivamente actos jurídico procesales con eficacia, en nombre propio o por cuenta ajena, que poseen las personas que tienen el libre ejercicio de los derechos que en el proceso se hacen valer (siendo el reflejo procesal de la capacidad de ejercicio), ${ }^{31}$ podemos observar así que esta solo puede predicarse respecto de quienes tengan personalidad, esto es, las personas físicas y jurídicas. Consecuentemente, y dadas las mismas razones esgrimidas al tratar la capacidad para ser parte, debemos concluir que los grupos tampoco poseen capacidad procesal. ${ }^{32}$

Finalmente, podemos concluir que si bien el ordenamiento no habilita a los grupos para ser parte, al no reconocerles las capacidades procesales antes vistas, sin embargo - puesto que ello no quiere decir que deja de otorgar protección procesal a estos legítimos intereses colectivos- si les otorga legitimación para obrar. En ese sentido, el grupo tiene legitimación porque así se lo reconoce expresamente el ordenamiento, y en cambio, no posee capacidad porque simplemente no puede tenerla. ${ }^{33}$

3) La particular legitimación para obrar:

Podemos definir al concepto de legitimación para obrar como la cualidad que corresponde a los sujetos de la relación jurídica sustancial, cuando esta última sea deducida en juicio, para ser parte activa y pasiva respectivamente- en la relación jurídica procesal que se forme, pues solo cuando estas personas figuren como partes en el proceso, la pretensión procesal podrá ser examinada en cuanto al fondo. Siendo necesario salir del derecho procesal para saber que sujetos han de figurar como partes en un proceso, puesto que la legitimación viene más bien regulada por el derecho sustancial. Reconocer también, que ésta, la mayoría de las veces, se resolverá en la mera afirmación de la titularidad activa por el actor, imputándole la titularidad pasiva al demandado, dado que la existencia o no de dicha titularidad solo resultará de la sentencia en definitiva. ${ }^{34}$

Sin embargo, este concepto de "legitimidad ordinaria» resulta insuficiente para explicar a los intereses difusos o de grupo, así como también

31 Matheus, Parte, tercero [...], op. cit., p. 39.

32 Con similar parecer Silguero, La tutela [...], op cit., pp. 145-146.

33 Silguero, La tutela [...], op. cit., pp. 134-146.

34 Matheus, Parte, tercero [...], pp. 51-52; con similar parecer Lozano-Higuero entiende que se trata de uun concepto puramente jurídico, no contaminado por los hechos relacionados con el fondo, en tanto en cuanto muestra la consistencia de la pretensión material, porque indica si la correlación jurídica entre sujeto-objeto es conforme a derecho" 
aquel de «legitimidad extraordinaria» en la cual no se afirma la titularidad de la posición afectada y hecha valer en el proceso, sino la de una posición subjetiva en una relación conexa con aquella, cuya satisfacción depende de la satisfacción de la posición que se hace valer. ${ }^{35}$ Puesto que en los intereses difusos la titularidad de estos correspondería más bien a la colectividad, y dado que la legitimación es la afirmación de la titularidad de una posición subjetiva en una relación jurídica, cuando se trata de estos intereses en los cuales no existe una relación inmediata entre el sujeto y el objeto, se difumina la titularidad, y consecuentemente se dificulta la determinación de la legitimidad.

Lo que supondría la imposibilidad de tutelar los intereses de grupo ajenos a una individualización excluyente y personalista (comprendiéndose así solo a los intereses individuales genéricos, y dejando de lado a los intereses colectivos tales como la defensa del medio ambiente). ${ }^{36}$ Por esta razón, deviene en necesario el reconocimiento de una legitimidad para obrar colectiva, dado que el grupo está constituido por un número mayor o menor - de miembros, de los cuales uno o más tomarán la iniciativa de actuar en nombre de los otros, asumiendo la función de gestores del grupo, razón por la cual su actuación procesal obliga a exigir —además del interés común ya visto- la correspondiente legitimación colectiva, la cual constituye la base de la tutela procesal del grupo al reconocerlo como sujeto legitimado, ${ }^{37}$ debiendo colocarse las restricciones procesales antes vistas, en su debido lugar. ${ }^{38}$ Por todo esto, cabe distinguir aquellos fenómenos en que los sujetos son identificables por la titularidad de las relaciones contractuales de que se trata, de una vía de tutela

35 Bujosa, La protección [...], op. cit., p. 260; con este mismo parecer entendemos que «la legitimación extraordinaria se concede a sujetos que no fueron parte de la relación jurídica material o los cuales no afirman la titularidad de esta últiman (Matheus, Parte [...], op. cit., pp. 51-52).

36 Bujosa, La protección [...], op. cit., pp. 260-261.

37 Silguero, La tutela [...], op cit., p. 176. El autor, a efectos de salvar la falta de capacidades procesales del grupo, con lo que se imposibilita su incorporación como parte en el proceso, distingue los conceptos de parte procesal y sujeto legitimado, donde si bien el grupo no puede ser parte en el proceso porque carece de capacidad para ser parte y capacidad procesal, si resulta ser sujeto legitimado dado que posee legitimación para obrar.

38 Con este parecer Jordano, op cit., p. 300. Refiriéndose específicamente el autor a la insuficiencia en materia de legitimación de la Ley de la Jurisdicción contencioso-administrativa española. 
más general y preventiva, ejercitada por personas que hacen valer un interés más general, encontrándonos en ambos frente a formas de legitimación colectiva. ${ }^{39}$

\subsection{Criterios de legitimación: tutela pública y tutela privada de los intereses difusos}

Podemos observar que los diversos ordenamientos optan por otorgar distintas vías de legitimación para la tutela jurisdiccional de estos intereses, siendo así acogidos como intereses públicos (interés colectivo) o como intereses individuales con relevancia colectiva (intereses individuales genéricos), y consecuentemente en un caso participan organismos públicos, mientras que en el otro, lo hacen los individuos o grupos.

\subsubsection{Tutela pública de los intereses difusos}

Sobre la base de la distinción anterior, los intereses para los que la relación con el individuo es más bien mediata e indirecta (intereses colectivos), entre los cuales se encuentra la defensa del medio ambiente, a fin de encontrar más fácilmente protección procesal han sido acogidos como intereses públicos, con el consecuente otorgamiento de su titularidad a órganos públicos, facilitándose por medio de estos su tutela jurisdiccional. ${ }^{40}$

Dentro de esta perspectiva, podemos observar los siguientes casos:

\section{A. Ministerio público:}

Un primer ente que puede defender los intereses difusos es el ministerio público, el cual tiene a su cargo la defensa de la legalidad, así como del interés público y social, razón por la cual, se erige como importante instrumento para la defensa de los intereses de grupo, con una especial importancia en el ámbito penal. ${ }^{41}$ Encontrándose esta opción recogida en nuestro ordenamiento, el cual le otorga legitimidad para obrar activa, permitiéndole además la posibilidad de su intervención procesal cuando exista ya litispendencia. ${ }^{42}$

39 Con este criterio Bujosa, La protección [...], op. cit., p. 262.

40 Bujosa, La protección [...], op cit., p. 237.

41 Bujosa, op. cit., pp. 240-241.

42 Así nuestro Código Procesal Civil señala en su artículo $82^{\circ}$ que «Pueden promover o intervenir en este proceso, el Ministerio Público [...]". Del mismo modo, la Ley del 
B. Defensor del pueblo:

El ombudsman sueco, quien ahora tiene análogos por todas partes, es otra institución explícitamente creada para representar los intereses colectivos y fragmentados. ${ }^{43}$ Siendo reconocida por la doctrina, la virtualidad catalizadora de esta figura y el ancho quehacer que le espera en relación a la tutela jurisdiccional de todos los fenómenos que en el interés difuso confluyen, concluyendo además, que su función principal debe consistir en la tutela de este tipo de intereses. ${ }^{44}$

De otro lado, resulta muy interesante en materia de protección de intereses difusos la creación de ombudsman especializados, particularmente importante en materia de derechos y libertades de tercera generación. ${ }^{45}$

Finalmente, podemos señalar que nuestro ordenamiento reconoce también una legitimidad para obrar activa al defensor del pueblo. ${ }^{46}$

C) Otros organismos especializados:

Existen en los diferentes sistemas jurídicos, otros entes públicos también legitimados para la protección de este tipo de intereses, entre los cuales podemos encontrar:

Para el caso del Reino Unido, al Director General of Far Trading (creado por Far Trading Act de 1973) el cual debe supervisar las actividades comerciales a efectos de eliminar las prácticas desleales y las situaciones de monopolio.

proceso contencioso administrativo (Ley $N^{\circ} 27584$ ) en su artículo $12^{\circ}$ inciso $1^{\circ}$ nos señala que "Cuando la actuación impugnable de la administración pública vulnere o amenace un interés difuso, tendrán legitimidad para iniciar el proceso contencioso administrativo: 1 . El Ministerio Público, que en estos casos actúa como parte[...]". Por su parte, el artículo $14^{\circ}$ inciso $2^{\circ}$ de la misma norma, nos señala que en este proceso interviene el Ministerio Público «Como parte cuando se trate de intereses difusos, de conformidad con las leyes de la materias.

43 Mauro Capelletti y Bryant Garth, El acceso a la justicia. La tendencia en el movimiento mundial para hacer efectivos los derechos, Fondo de Cultura Económica, México, 1996, p. 38. Refiriéndose los autores específicamente al ombudsman del consumidor propio del ordenamiento sueco.

44 Con similar criterio Lozano-Higuero, La protección [...], op. cit., p. 250.

45 Bujosa, La protección [...], op. cit., p. 250. Entre los cuales podemos encontrarpara el caso sueco- el Antitrust ombudsman (creado en 1954) y el ombudsman de los consumidores (creado en 1971) antes ya señalado.

46 En ese sentido, la Ley del Proceso Contencioso Administrativo (Ley No 27584) en su artículo $12^{\circ}-$ ya antes citado - nos señala que "Cuando la actuación impugnable de la administración pública vulnere o amenace un interés difuso, tendrán legitimidad para 
De otro lado, en Irlanda existe el Director of Consumer Affairs (creado por Act. de 1978) el cual tiene competencia en materia de indicaciones comerciales - y de precios - falsas, así como en materia de publicidad.

Por su parte los Estados Unidos de Norteamérica, posee —además de muchos otros órganos administrativos similares- la Federal Trade Commissión (creada en 1914) que vigila las actividades empresariales anticompetitivas y las prácticas de negocios injustas y engañosas. ${ }^{47}$

Por último, debemos señalar que en nuestro ordenamiento existe también atribuida una legitimación activa en materia de intereses difusos a ciertos organismos especializados. ${ }^{48}$

D) Una alternativa distinta:

La Ley italiana del 8 de julio de 1986, No 349, crea el Ministerio del Ambiente y regula la materia del daño ambiental, inscribiéndose lamentablemente dentro de la tendencia a identificar a los intereses colectivos como intereses públicos de titularidad del estado, posibilitando tan solo la legitimación de las asociaciones individualizadas de forma sumamente indirecta (como obvia consecuencia de atribuir los bienes ambientales al estado). ${ }^{49}$ Únicamente pueden intervenir en el proceso y proponer recurso para el caso de anulación de actos ilegítimos. Observándose así, que esta norma no recoge la evolución de este particular interés difuso como un verdadero y propio derecho social del ambiente, ni otorga una adecuada solución al problema de la legitimación, no resultando convincente defender - como lo hace- la intervención de estas asociaciones, desconociendo la existencia de un interés propio y autónomo de la asociación, el cual por si solo la legitimaría para su actuación procesal en defensa de su propia posición. ${ }^{50}$

iniciar el proceso contencioso administrativo: [...] 2. El Defensor del Pueblo [...]». De igual forma, el artículo $9^{\circ}$ inciso 2 de la Ley Orgánica de la defensoría del pueblo (Ley No 26520) señala que este puede interponer «la Acción de Amparo [...] en tutela de los derechos constitucionales y fundamentales de la persona y de la comunidad".

47 Bujosa, La protección [...], op. cit., pp. 253-255.

$48 \mathrm{En}$ tal sentido, el artículo $51^{\circ}$ de la Ley de protección al consumidor (Decreto Legislativo No 716) nos señala que "el Indecopi, previo acuerdo de su Directorio, se encuentra legitimado para promover procesos judiciales relacionados a los temas de su competencia, conforme a lo señalado por el artículo $82^{\circ}$ del Código Procesal Civil [...]. El Indecopi podrá delegar esta facultad en entidades públicas y privadas que estén en capacidad de representar el interés de los consumidores».

49 Bujosa, La protección [...], op. cit., pp. 257-258.

50 Silguero, La tutela [...], op cit., p. 224. 


\subsubsection{Tutela privada de los intereses difusos}

Nos toca ahora examinar la tutela colectiva - y privada - de estos intereses, la cual se encuentra dirigida a poner en comunicación al núcleo social con la jurisdicción, correspondiendo - en propiedad - a este tipo de tutela la legitimación para obrar colectiva a la cual antes ya no hemos referido. ${ }^{51}$

Podemos observar, dentro de esta perspectiva, los siguientes casos:

\section{1) Asociaciones}

Dentro de las cuales a su vez cabe reconocer dos modelos de participación de la colectividad. Por un lado, las asociaciones ordinarias en las que el grupo de afectados negativamente por una misma conducta forman una asociación. Por otro, las asociaciones cualificadas que son creadas para la defensa de determinados valores, como es el caso del medio ambiente. A su vez, todas estas pueden actuar por tres vías: defender sus propios derechos e intereses legítimos como persona jurídica; defender los derechos e intereses de sus asociados en el ámbito de los fines que les son propios; o defender derechos o intereses de los sujetos de la misma categoría, clase o sector de los asociados, afectados por acciones u omisiones causadas por los mismos o iguales hechos. ${ }^{52}$

Cabe además señalar, que nuestra normatividad también reconoce legitimidad activa - para este tipo de intereses-a las asociaciones. ${ }^{53}$

2) Acción popular

La acción popular implica el acceso a los tribunales de cualquier ciudadano para exigir la intervención de los órganos jurisdiccionales con la finalidad de que se cumpla la legalidad, sin necesidad de ocupar una posición subjetiva de ventaja lesionada o amenazada. Se trata de una tutela objetiva del ordenamiento que pretende que la realidad se ajuste a las

51 Con similar parecer Bujosa, La protección [...], op. cit., p. 260.

52 Bujosa, La protección [...], op. cit., pp. 276-277.

53 En ese sentido, nuestro Código Procesal Civil señala en su artículo $82^{\circ}$ que «Pueden promover o intervenir en este proceso [...] las asociaciones o instituciones sin fines de lucro que según la ley y criterio del juez, este último por resolución debidamente motivada, estén legitimadas para ello». Del mismo modo, la Ley del proceso contencioso administrativo en su artículo $12^{\circ}$ inciso 3 nos señala que "Cuando la actuación impugnable de la administración pública vulnere o amenace un interés difuso, tendrán legitimidad para iniciar el proceso contencioso administrativo: [...] 3. Cualquier persona [...] jurídica». 
prescripciones normativas, no existiendo una relación inmediata entre el objeto de la pretensión y quien la ejercita, sino un mero interés en la defensa de la legalidad vigente. Siendo también posible por esta vía someter a los intereses difusos, que encuentran dificultades de personalización y tienden a ser considerados ajenos a todos los que intentan su protección jurisdiccional, a la tutela judicial efectiva. ${ }^{54}$

Finalmente, consideramos que resulta factible el uso de la acción popular a efectos de salvaguardar algún interés colectivo que se encuentre vulnerado por efecto de alguna norma legal. ${ }^{55}$

\section{3) Acciones de grupo}

Se trata de los supuestos - propios del common law- conocidos como Class Actions (acciones de clase) los cuales constituyen un medio de obtención de tutela jurisdiccional basado en el poder procesal reconociendo a un individuo para actuar en nombre propio y de otras personas similarmente situadas que constituyen una clase. ${ }^{56} \mathrm{Y}$ en tal forma, una o varias personas pueden actuar procesalmente defendiendo, además de sus intereses, los de aquellos que estén en una situación similar, aunque no haya habido un apoderamiento expreso, puesto que se hace en interés de todos los que se encuentran en una posición jurídico-material similar. ${ }^{57}$ Por otra parte, para que uno o más miembros de una clase puedan demandar o ser demandados como partes representativas, se requiere que: a)

54 Bujosa, La protección [... ], op. cit., p. 286; con similar parecer Lozano-Higuero, La protección [...], op. cit., pp. 252-253. Nos señala que "para nosotros es claramente admisible una legitimación uti universi - de la categoría-, y hasta deseable como objetivo final una uti cives - acción popular — [...], sin embargo, [...] aun en la modalidad de acción popular uti cives - no es propugnable una exclusividad legitimatoria reducida esta hipótesis, sino concurrente, combinada con los restantes supuestos eventualmente pensables».

55 En este sentido, el artículo $200^{\circ}$ inciso 5 de la Constitución nos señala que la acción popular procede "por infracción de la Constitución y de la ley, contra los reglamentos, normas administrativas y resoluciones y decretos de carácter general, cualquiera sea la autoridad de la que emanen". Y en ese mismo sentido, el artículo $4^{\circ}$ de la Ley procesal de la acción popular (Ley No 24968) establece que «Pueden interponer demanda de acción popular: 1. Los ciudadanos peruanos en el ejercicio pleno de sus derechos. 2. Los ciudadanos extranjeros residentes en el Perú. 3. Las personas jurídicas constituidas o establecidas en el Perú, a través de sus representantes legales. 4. El Ministerio Público [...]».

56 Silguero, La tutela [...], op. cit., p. 271.

57 Bujosa, La protección [...], op. cit., pp. 287-288. 
la clase sea tan numerosa que el litisconsorcio sea impracticable, b) que existan cuestiones de hecho o derecho comunes a la clase, c) que las demandas o defensas de las partes representativas sean típicas de las correspondientes a la clase y d) que las partes representativas protejan adecuadamente el interés de la clase. ${ }^{58}$

Además sugiere en estos casos el análisis económico del derecho, que las acciones de clase serán apropiadas cuando los intereses en juego sean grandes en total y resulten a su vez pequeños para cada demandante individual. ${ }^{59}$

Por último, cabe indicar que nuestra normatividad reconoce la legitimidad activa de uno o más sujetos para el ejercicio judicial de estos intereses. ${ }^{60}$

\subsection{Nuestra posición}

Primero, dado que ante los intereses difusos el conocimiento doctrinal, los instrumentos legales con que desarrolla su actividad, así como los materiales del Ministerio Público aparecen como notoriamente escasos, resulta que este - como adecuado portador de estos intereses- adolece de serias deficiencias en su preparación técnica como para atribuirle una legitimación exclusiva de los intereses difusos. ${ }^{61}$ Siendo lamentable que, tanto en los países de derecho común como en los de derecho civil, esta institución gubernamental que por virtud de su tradición debería proteger el interés público - por su propia naturaleza - es incapaz de hacerlo, dado que resulta muy susceptible a las presiones políticas. Lo cual constituye una grave debilidad, pues los intereses difusos frecuentemente tienen que hacerse valer frente a entidades políticas y por el hecho que la justificación de estos nuevos derechos a menudo requiere experiencia técnica en áreas no jurídicas. ${ }^{62}$

58 Silguero, La tutela [... ], op. cit., p. 273.

59 Robert Cooter y Thomas Ulen, Derecho y economía, Fondo de Cultura Económica, México, 1997, p. 491.

60 En este sentido, la Ley del proceso contencioso administrativo en su artículo $12^{\circ}$ inciso 3 nos señala que "Cuando la actuación impugnable de la administración pública vulnere o amenace un interés difuso, tendrán legitimidad para iniciar el proceso contencioso administrativo: [...] 3. Cualquier persona natural».

61 Lozano-Higuero, La protección [...], op. cit., pp. 248-249.

62 Con este parecer Capelletti y Garth, El acceso [...], op. cit., pp. 36-37. 
De otro lado, por su organización es una institución jerárquica y centralizada, similar a una maquinaria difícil de mover, lo cual colisiona con el dinamismo característico de los intereses de grupo. Además, su ligazón con vínculos tanto de hecho como de derecho con el poder ejecutivo, puede ofrecer dudas en relación con una eficaz tutela de estos intereses frente a lesiones procedentes de la administración pública. Por otra parte, encontramos la falta de especialización de los fiscales, dada su poca preparación específica a efectos de poder enfrentar estas cuestiones. Sin olvidar las limitaciones que supone la falta de medios materiales y personales del Ministerio Público, la cual nos plantea serias dudas respecto a la posibilidad que tiene de llevar a cabo una adecuada defensa de estos intereses. ${ }^{63}$

Segundo, en relación al ombudsman —como ya se indicó- consideramos que la solución estrictamente gubernamental parece tener limitaciones inherentes aun cuando mejor funcione, dado que el entusiasmo y la energía del particular deben transmitirse a la maquinaria burocrática gubernamental, que con frecuencia se torna lenta, inflexible y pasiva en el cumplimiento de sus deberes. ${ }^{64}$ Quedando sentado, en todo caso, que no somos partidarios de una legitimación exclusiva, atribuida en materia de intereses difusos a este órgano, sino más bien, de una legitimación concurrente con otras hipótesis. ${ }^{65}$

Tercero, respecto de los otros organismos especializados, si bien son importantes, son también limitados, dado que tienen - por cierto número de razones- debilidades aparentemente inevitables. Las agencias públicas tienden a responder a los intereses organizados pues algo les va en el resultado de una decisión de la agencia, y esos intereses tienden a ser predominantemente los de las entidades que la agencia supuestamente controla. Por otra parte, los intereses difusos tales como aquellos de los ecologistas tienden a no estar organizados en el grupo coherente que sería necesario para influir sobre dichas agencias. ${ }^{66}$ Adicionalmente, podemos observar objeciones no menos importantes como la dependencia que poseen estos organismos respecto de la administración, la posibilidad de una psicología burocrática y una estructura jerárquica, un funcionamiento que tiende a ser rígido y lento, además del hecho que solo son creados

63 Bujosa, La protección [...], op cit., pp. 243-246.

64 Con este parecer Capelletti y Garth, El acceso [...], op. cit., p. 38.

65 Lozano-Higuero, La protección [...], op. cit., p. 250.

66 Con este parecer Capelletti y Garth, El acceso [...], op. cit., p. 37. 
tras largos y lentos procesos decisivos todo lo cual contrasta con el dinamismo que caracteriza a los intereses difusos. Arribándose así no a una conclusión contraria a la existencia de estos organismos, sino - como también ocurre con los antes vistos-a una necesidad de complementación con la actividad ante los tribunales procedente de la legitimación colectiva privada. ${ }^{67}$

Podemos finalmente señalar que la solución al tratamiento de la legitimación para obrar de este tipo de intereses requiere de una solución mixta, combinando la tutela pública con aquella privada, a efectos de su reciproca complementación y control, ${ }^{68}$ opción por la cual —quizá intuitivamente- ha optado de manera adecuada nuestro ordenamiento procesal. $^{69}$

\section{Entre representación y gestión procesal}

Como vimos anteriormente, el grupo, si bien no cuenta con las capacidades procesales, sí posee una legitimación para obrar colectiva, razón por la cual, debemos ahora determinar que calidad tiene el sujeto -0 sujetos- que obra en el proceso en pro del interés difuso. Pudiendo afirmarse así, que la función que cumple es la de gestor y no la de apoderado, ya que al actuar el interés colectivo del grupo también actúa en nombre propio, siendo por tanto parte, resultando así preferible considerarlo como un sustituto, ya que además de actuar un derecho ajeno (el

67 Con este parecer Bujosa, La protección [...], op. cit., pp. 256-257.

68 Con similar parecer Capelletti y Garth, El acceso [...], op. cit., p. 45. Nos señalan que «debe haber efectivamente una solución mixta o pluralista para el problema de representar intereses difusos. Dicha solución, por supuesto, no debe estar contenida en una sola propuesta de reforma. Lo que es importante es reconocer y confrontar el problema básico en esta área: expuesto simplemente, este interés requiere de una acción efectiva de grupos privados cuando sea posible, pero los grupos privados no siempre están disponibles y a menudo son difíciles de realizar".

69 Basta recordar todos los supuestos de legitimación para obrar antes vistos, así como también observar el tenor del artículo $82^{\circ}$ de nuestro Código Procesal Civil el cual nos señala que también «Pueden promover o intervenir en este proceso [...] los gobiernos regionales, los gobiernos locales, las comunidades campesinas y/o las comunidades nativas en cuya jurisdicción se produjo el daño ambiental [...]». 
derecho a la tutela judicial de los demás miembros), pide también en nombre propio. ${ }^{70}$

Es por ello que, faltando el carácter impropio del interés cuya tutela pretenden los gestores en el proceso, ni puede tratarse de una gestión de negocios ajenos ni tampoco de una representación, ya que, en el caso del representante, este como procurador de los asuntos del principal, acciona buscando alcanzar la tutela jurisdiccional de los derechos e intereses legítimos del representado y actuando en nombre y por cuenta de este. Tratándose más bien de una legitimación por sustitución, por la cual un sujeto (sustituto), actuando en su propio nombre e interés, pretende en el proceso la tutela jurisdiccional de un derecho o interés legítimo de otro sujeto (sustituido). Siendo este un criterio excepcional de legitimación, adecuado para permitir el acceso procesal al gestor del grupo, quien evidentemente no actúa para él mismo, sino para la clase o categoría titular del interés difuso que defiende, haciéndose portador, no tanto de su propio interés jurídico individual sino de un interés colectivo. Yen tal forma el gestor del grupo es parte en el proceso y recibe los efectos de la sentencia junto al sujeto legitimado sustituido. ${ }^{71}$

Finalmente, debe quedar claro que el representante del grupo no es un apoderado de los representados sino que se nombra a si mismo, pudiendo aquellos desconocer la pendencia del proceso en que se discuten sus propios intereses. Siendo por esta razón que — ante la ausencia de apoderamiento o mandato- preferimos denominarlo gestor, ya que asume sus funciones por propia iniciativa y de forma voluntaria. Sin embargo, una

70 Silguero, La tutela [...] op cit., p. 149; con diferente criterio Bujosa, La protección [...], op. cit., pp. 161-186. Entiende que «La actuación en el proceso del resto de sujetos jurídicos, con o sin personalidad se resuelve no en términos de capacidad, sino de representación. Se transfieren, pues, los problemas de falta de capacidad al momento de la representación, con lo cual si quien en principio no tenia capacidad, actúo con una representación idónea, habrá realizado actos procesales válidos [...]. Realmente el concepto de representación aquí se transforma: ya no se trata de una representación referida a una persona física o jurídica (Vertretung), sino una representación de los intereses de un grupo indeterminado de sujetos (Reprüsentation)".

71 Silguero, La tutela [...], op. cit., p. 165. Resulta evidente que esta figura no puede entenderse como una representación procesal, por la sencilla razón que en aquella el representante no es parte en el proceso siéndolo más bien el representado, el cual si es titular de la pretensión, de la demanda y es el que queda - consecuentemente- sujeto a la cosa juzgada (Matheus, Parte, tercero [...], op. cit., pp. 25-26). 
vez en el proceso deberá continuarlo hasta su finalización — salvo que por autorización judicial, sea sustituido, o bien, se nombre un defensor judicial al grupo-no permitiéndosele el desistir, allanarse, conciliar o transigir sin previa autorización judicial, y en tanto no exista una regulación adecuada y expresa de esta figura cabría aplicar subsidiariamente las normas sobre "gestión de negocios» de nuestro Código Civil. ${ }^{72}$

\section{Extensión de la cosa juzgada}

Si bien respecto a la legitimación por sustitución, queda clara la necesidad de que la sentencia surta efectos no solo respecto del sustituto sino también del sustituido, al ser este titular del derecho o interés legítimo objeto del proceso. Ello no es tan simple cuando el sustituido es un grupo, dada su incapacidad para asumir derechos, obligaciones y cargas del proceso, pese a ser el referente de la pretensión y estar legitimado. Donde si bien la extensión de la eficacia de la sentencia a los miembros del grupo tiene a su favor la pertenencia común del interés hecho valer en el proceso, existen otros problemas como son la necesidad del respeto al principio de audiencia - el cual impide que la sentencia pueda afectar a quienes no hayan sido partes en el proceso- como también la imposibilidad práctica del emplazamiento a todos los miembros a efectos se apersonen como partes, la necesidad de evitar sentencias contradictorias $y$ el logro de la economía procesal. ${ }^{73}$

Una vez sopesadas todas estas circunstancias, existen razones para defender la extensión parcial de los efectos de la sentencia mediante la cosa juzgada "secundum eventum litis», es decir, únicamente en lo que pueda resultar favorable a los miembros del grupo que no contendieron. De tal forma, nos parece excesivo defender una extensión «ultra partes» sean o no favorables los efectos de la resolución judicial, dado que esta hipótesis tropieza con la probable vulneración del principio de audiencia, no poseyendo además ninguna utilidad en las hipótesis de grupos de gran tamaño ${ }^{74}$

Es por todo lo antes expresado que se postula el alcance de la cosa juzgada a aquella ultra partes secundum eventum litis, esto es, se extienden

72 Con este parecer Silguero, La tutela [...], op. cit., p. 180.

73 Ibid, p. 361.

74 Ibid, pp. 361-363. 
a todos, solo los efectos favorables de la resolución y no los efectos perjudiciales, debiendo utilizarse publicidad extraprocesal — principalmentepara el acto introductivo como para la sentencia, otorgándose además un plazo razonable para que cualquier miembro del grupo pueda impugnar esta última. ${ }^{75}$

Por último, debemos señalar que esta regla se encuentra plenamente reconocida en nuestro actual ordenamiento. ${ }^{76}$

75 Con este criterio Lozano-Higuero, La protección [...], op. cit., pp. 261-262.

76 En tal forma, el artículo $82^{\circ}$ de nuestro Código Procesal Civil nos señala que «[...] La sentencia definitiva que declare fundada la demanda, será obligatoria además para quienes no hayan participado del procesom. Siendo además idéntico el criterio -general-del proceso de amparo (cuando aquel sea utilizado), señalando el artículo $8^{\circ}$ de la Ley de habeas corpus y amparo (Ley No 23506) que "La resolución final constituye cosa juzgada únicamente si es favorable el recurrente». 